First Peoples Child \& Family Review

An Interdisciplinary Journal Honouring the Voices, Perspectives, and Knowledges of

First Peoples through Research, Critical Analyses, Stories, Standpoints and Media

Reviews

\title{
Can Spiritual Ecograms be Utilized in Mental Health Services to Promote Culturally Appropriate Family and Couples Therapy with Indigenous People?
}

\section{Nicole Elliott}

Volume 7, Number 1, 2012

URI: https://id.erudit.org/iderudit/1068869ar

DOI: https://doi.org/10.7202/1068869ar

See table of contents

Publisher(s)

First Nations Child and Family Caring Society of Canada

ISSN

1708-489X (print)

2293-6610 (digital)

Explore this journal

Cite this article

Elliott, N. (2012). Can Spiritual Ecograms be Utilized in Mental Health Services to Promote Culturally Appropriate Family and Couples Therapy with Indigenous People? First Peoples Child \& Family Review, 7(1), 118-126. https://doi.org/10.7202/1068869ar

\section{Article abstract}

Research addressing the potential utilization of spiritual ecograms with Indigenous families and children, specified by experienced professional in the field of Native-American psychology, was critiqued and reviewed in order to attend to its influence and applicability regarding the literature of Indigenous family therapy, and how it could be beneficial in therapy with Indigenous families. The literature review presents an effective tool, providing an in-depth exploration of spiritual strengths of the family and or children that incorporates spirituality into techniques commonly used in family therapy practice. Study results (Limb \& Hodge, 2011) show that this tool is consistent with Native-American culture (Brucker \& Perry, 1998; Green, 2010; Paniagua, 2005; Trujillo, 2000) and highlights many beneficial qualities for its utilization in practice. Limitations and recommendations for future research are also discussed.
This document is protected by copyright law. Use of the services of Erudit (including reproduction) is subject to its terms and conditions, which can be viewed online.

https://apropos.erudit.org/en/users/policy-on-use 


\title{
First Peoples Child \& Family Review
}

An Interdisciplinary Journal Honoring the Voices, Perspectives and Knowledges of First Peoples

through Research, Critical Analyses, Stories, Standpoints and Media Reviews

\section{Can Spiritual Ecograms be Utilized in Mental Health Services to Promote Culturally Appropriate Family and Couples Therapy with Indigenous People?}

\author{
Nicole Elliott ${ }^{a}$ \\ ${ }^{a}$ M.A. Candidate in the Counselling Psychology Program, University of Toronto, Toronto, Canada
}

\begin{abstract}
Research addressing the potential utilization of spiritual ecograms with Indigenous families and children, specified by experienced professional in the field of Native-American psychology, was critiqued and reviewed in order to attend to its influence and applicability regarding the literature of Indigenous family therapy, and how it could be beneficial in therapy with Indigenous families. The literature review presents an effective tool, providing an in-depth exploration of spiritual strengths of the family and or children that incorporates spirituality into techniques commonly used in family therapy practice. Study results (Limb \& Hodge, 2011) show that this tool is consistent with Native-American culture (Brucker \& Perry, 1998; Green, 2010; Paniagua, 2005; Trujillo, 2000) and highlights many beneficial qualities for its utilization in practice. Limitations and recommendations for future research are also discussed.
\end{abstract}

\section{Overview}

Spirituality is an important component in family therapy, and is considered an essential element for delivering treatment that is culturally competent with Indigenous ${ }^{1}$ clients (Wendt \& Gone, 2011). In order for therapy to reach cultural competence, the therapist must learn and demonstrate the congruent behaviors, attitudes and policies that will enable the therapist to work effectively in cross-cultural situations. Cultural competence can be viewed as a process beginning with sensitivity, awareness, and knowledge and then acquiring the appropriate skills necessary for adapting to cross-cultural issues and including them into therapy. This review of the literature

Corresponding author:

Nicole Elliott, Ontario Institute for Studies in Education, University of Toronto, 252 Bloor St. West, Toronto, ON, Canada M5S 1V6 nic.elliott@mail.utoronto.ca examines the potential use of a spiritual assessment tool, the spiritual ecogram, as modified by Limb \& Hodge (2011) for use in psychotherapy with Native American $^{2}$ families.

Although spirituality is viewed as being an essential element in providing culturally competent

1 Indigenous is used in this review to identify the cultural group of the People who are Native to colonized land (Canada, United States of America, Australia). This term is used broadly in a global sense.

2 Native American defines the Native people to the United States of America and is used separately to "Indigenous" when specifying the results from the study conducted by Hodge and Limb (2011), which examined the cultural consistency based on the expert knowledge and ratings from professionals with a specific background in Native American culture. 
First Peoples Child \& Family Review, Volume 7, Number 1, 2012

family therapy, it is often neglected in the training of therapists (DiLorenzo, Johnson, \& Bussey, 2001; Frame, 2000; Grams, Carlson \& McGeorge, 2007). This can become problematic when providing mental health and healing services to Native American families because many Indigenous people view spirituality as being a fundamental role in their lives and some believe that their challenges arise from imbalances in their spiritual relationships. Therefore, when working with these families, spiritual assessments are necessary to help the family achieve an appropriate family balance and mental health. Including spirituality into therapy for this population is critical for communication and change (Cross, 2002; Limb \& Hodge, 2008; Rothery \& Enns, 2001).

Many tools have been created to help therapists incorporate spirituality into the intervention strategies of Native American families (Hodge \& Limb, 2010). The most cited of these tools in the literature are: spiritual life maps (Hodge, 2005a), illustrated descriptions and maps of an individual's spiritual life; spiritual genograms (Hodge, 2001), illustrate the flow of spirituality across at least three generations; spiritual ecomaps (Hodge \& Williams, 2002), focus on clients' current spiritual relationships as they are happening in the present; and the spiritual ecograms (Hodge, 2005b). The spiritual ecogram is one of these spiritual strength assessment tools, not yet utilized, that can integrate spirituality into therapy and allows the family's participation in planning for their future in a natural interactive way. Spiritual ecograms are unique to family therapy because they combine the strengths of genograms ${ }^{3}$ and ecomaps ${ }^{4}$ into one single diagram, depicting the family connections between past and present functioning.

The main problem identified in the study composed by Limb \& Hodge (2011), is that spirituality is valued highly in Native American culture, and therefore, lack of training has created barriers in communication and treatment. For instance, some therapists may not be aware of the importance of spirituality in Indigenous people's lives, or the traditions and practices that are involved. Furthermore, therapists may not have an understanding of the traumatic history that Indigenous people have endured through colonization, where for some of the Indigenous generations, it was illegal to practice traditional ways. The following study in review was conducted to examine how congruent spiritual ecograms are with Native American culture.

\section{Method}

Fifty Native American therapists, practitioners, social workers, counselors, and psychologists with extensive practice and knowledge regarding Native American culture were identified and asked to participate in the study by completing an online survey. A majority of these professionals $(84 \%)$ identified themselves as being Native American ${ }^{5}$.

The survey instrument developed for the study used a modified version of the spiritual ecogram ${ }^{6}$ assessment tool by the authors Gordon Limb and David Hodge (2011), in order to incorporate Native American culture into the context, and to make the instrument more consistent for use with Native American families and children. Spiritual ecograms provide a graphic snapshot of

\footnotetext{
3 A geneogram is similar to a family tree but includes additional relationships amongst the individuals.

4 An ecomap is a graphical representation that shows all of the systems at play in an individual's life.

5 The professionals self-identified their Native American heritage, and the participants identified tribal nations of Lakota, Navajo/Dine, Cherokee, Chippewa/Gibwa, Mixed blood/ American Indian, or other tribal affiliation.

6 For an example of the spiritual ecogram see Limb \& Hodge (2011) page 3.
}

(c) Nicole Elliott 


\section{Can spiritual ecograms be utilized in mental health services ...}

the overall spiritual composition of the family system while also depicting features of stability/ fluidity and commitment to certain beliefs and traditions (Hardy \& Laszoloffy, 1995). Thus, the spiritual ecogram was modified to include Indigenous traditions and beliefs such as ceremonies, creator, community, and spiritual beings. The final survey was composed of two primary components. The first featured a general overview of spiritual ecograms, and provided an example. The Native American experts evaluated the cultural consistency of the assessment tool and rated the validation of use in therapy with Native American families. Following, the participants were presented with a set of questions to help operationalize the genogram aspects (featuring questions of historical elements), and ecomap aspects (questions featuring present relationships with rituals, creator, spiritual being, and transpersonal being). Consistency was measured via an 11-point scale (0 being not consistent at all with Native American culture, and 10 being completely consistent with Native American culture). The experts were then asked to list the strengths and weaknesses of each question set.

The survey was first pilot tested among five individuals who were attending an American Indian academic meeting and were asked to review the instrument. The survey was then refined based on feedback, and was delivered to participants by email via a URL link. Due to time constraints to complete the survey instrument, participants were rewarded $\$ 50.00$ following completion of the survey. Both parametric ${ }^{7}$ and non-parametric ${ }^{8}$ tests were conducted when applicable. The background characteristics of the participants were analyzed using tests of association between the variables and the demographic items. For analysis of the qualitative items, such as the openended questions used to identify the strengths and weaknesses of spiritual ecograms, a constant comparative methodology ${ }^{9}$ was used to examine data for similarities, patterns, and common themes (Glasser \& Strauss, 1967).

\section{Results}

There was a considerable variance among the 50 professionals in the ratings of the overall consistency of the spiritual ecograms with Native American culture. Although the perceptions of the overview were consistent across most demographic variables (no significant differences emerged), those participants who identified themselves as being 50 years of age or older, tended to rate the conceptual overview of the spiritual ecogram as less consistent with Native American culture (Limb \& Hodge, 2011). This demographic difference was also illustrated when participants rated the question sets. Overall, the participants evaluated the spiritual ecogram as having a moderate level of consistency with Native American culture. The most recognized strength of the spiritual ecogram was that it allowed for a holistic approach ${ }^{10}$ to therapy with the Native American family or client. The most common theme identified was that ecograms allow the family to see the big picture, and acknowledge how everything is interconnected. A common

\footnotetext{
7 Parametric tests make assumptions about the nature of a specific population from which the observations were drawn from. These tests suggest the importance of the population in the context of the observation and provide interpretation. The $t$ and $F$ tests, and the Pearson correlation coefficient are the most familiar of these tests (Siegal, 1957).

8 Non-parametric tests do not make assumptions about a population. Most non-parametric tests are used with nominal data such as the chi-square test, Fisher exact probability test and the Spearman rank correlation (Siegal, 1957).

9 Constant comparison analysis involves taking one piece of data (one interview, statement or theme) and comparing it to all others in a data set in order to generate knowledge about common patterns and themes within human experience (Thorne, 2000).

10 A holistic approach identifies that the whole of a complex system, is functionally greater than the sum of its parts and according to the Native world-view, a holistic approach recognizes that an individual is healthy when the physical, spiritual, social/emotional, and intellectual/ mental components of the self are in balance.
} 
First Peoples Child \& Family Review, Volume 7, Number 1, 2012

limitation of the ecogram was that it came across as complicated and visually overwhelming. It was also identified that the utilization of the ecogram in family therapy can become problematic when being used with Indigenous people who follow a collectivist view ${ }^{11}$. They might have difficulty identifying themselves in the center of the system.

Next, the cultural consistency of the spiritual genogram and ecomap question sets were evaluated. The spiritual genogram question set involved sample questions pertaining to historical elements. The experts rated these components as being moderately consistent with Native American culture.

The spiritual ecomap question set included sample questions in four areas: rituals, God or creator, spiritual community, and transpersonal being. All were rated consistent with Native American culture. The ritual questions were rated the highest, followed by the transpersonal being, spiritual community, and God/creator questions. Common themes that were identified as limitations to both question sets were that some of the terms were not appropriate to use when working with more traditional families. Some tribes have spiritual practices and symbols that are considered sacred and not to be shared with outsiders. For example, in typical genogram sections, families are asked to reflect and speak of those who have passed on. One of the experts suggested that, "some tribal cultures teach it is taboo to speak of or mention the dead. For those cultures, the genogram section may be inappropriate."

\section{Contextualizing the Reviewer's Position}

As a non-Aboriginal person learning and immersing myself in the area of Aboriginal psychology, it is imperative that I acknowledge that this is my own view and that I write from my own position as a student and aspiring mental health professional. What I write does not represent the voice of indigenous people, and speaks for only my own thoughts and interpretations of the discussed literature. Before addressing the mentioned research, it is important of the context in which I will be critiquing the said literature.

I am of Scottish and Irish Ancestry, and was raised on a farm, which my father inherited from his father, on the outskirts of a small hamlet called Shetland in South-Western Ontario. Growing up on a farm shaped my strong work ethic, patience, and respect, which I exude in my academic career. I have become acquainted with Aboriginal psychology through my graduate work at the University of Toronto, and posses a deep respect and interest in providing appropriate care and literature that can further benefit the community. Through my involvement in Aboriginal research, I have become engrained in the Aboriginal community of Toronto, through various projects and events. My interest in Aboriginal issues sparked through research involvement with the Canadian Federal Correction system, and from there, my research interests have expanded to cultural identity, spirituality, employment issues, and culturally appropriate programs and resources. This literature review is important to me, as I am currently an aspiring therapist and researcher in the Aboriginal community.

11 Collectivist culture is one where people tend to view themselves as members of a larger group, tribe or nation, and usually consider the needs of the group to be more important than the needs of the individual.

(C) Nicole Elliott 


\section{Can spiritual ecograms be utilized in mental health services ...}

\section{Critique}

This study acknowledges the importance of incorporating spirituality into therapy with Native American families and provides therapists with an appropriate assessment tool as they seek to enhance cultural competence in their therapy with Native American families and children. This research is a strong contribution to the literature because it highlights the deficits in family therapy techniques when working with Indigenous families and children, and provides an effective solution for repairing these gaps. Although the study demonstrated that the spiritual ecogram can be utilized as a powerful resource in the field of marital and family counseling, there were a few limitations to the methodology that must be recognized.

First, participants were selected and identified as experts in the area of Native American culture by one of the authors of the study. Since the author used non-probability sampling in the method of convenience sampling ${ }^{12}$, there is likely to be bias in the results. Furthermore, in addition to convenience sampling, purposive/snowball sampling ${ }^{13}$ was used, where the identified experts were asked to contact any other experts in Native American culture. This becomes biased because there are potentially many other experts from different tribal or spiritual perspectives that could have been included in the study. Furthermore, members of the Native American community themselves, who would be receiving such services should have been included in determining the cultural competency of such a sensitive tool. Consultation from Elders and healers would have strengthened the findings of the research.

Also, there was no pre-test administered to the participants to confirm their expertise status as a professional or academic in the area of Native American culture. To critique an instrument in mental health services, the experts should have had knowledge and experience in individual and family therapy techniques. Since the elements that classified the participant as being an "expert" on the topic are unknown, it is difficult to apply these results for the benefits of other helping professionals, and thus presents a threat to external validity. Although this instrument is intended for use on a very specific population, the use of non-probability sampling methods creates a barrier for using this assessment as a guide service for other similar population such as Canadian Aboriginals ${ }^{14}$, and this speaks to greater issues of generalizability with a population that has great within-group differences. Furthermore, the authors (Limb \& Hodge, 2011) did not specify the criteria in which experts defined themselves as being Native American, which also poses a threat to validity.

Finally, definitions for important concepts in the study, such as spirituality or religion were not identified. This could potentially threaten the results of the study since these words could have a variety of meanings specific to each participant. It is also important to recognize that professionals with extensive knowledge of Native American culture could only utilize the instrument presented in the research, especially since the majority of the participants were Native American themselves. The purpose of the research as defined in the research problem was to develop an instrument for therapists to use with Native American families in order to reach cultural competence in therapy. The assessment would be rather difficult for therapists who have not been trained to work with Indigenous populations.

\footnotetext{
12 Convenience sampling involves participants who are both easily accessible and willing to participate in a study (Teddlie \& Yu, 2007).

13 Purposive sampling selects individuals based on a specific purpose associated with the research question (Teddlie \& Yu, 2007).

14 Canadian Aboriginal people are those who are Native to Canadian land, including groups of the First Nations, Métis, and Inuit.
} 
Apart from its limitations, the study also had many positive outcomes. The results demonstrated that spiritual ecograms were consistent with Native American culture and could potentially be utilized in family therapy techniques. Although the limitations point out that a large amount of bias may exist, the themes that occurred from the participant's feedback could be embraced in the refining of this assessment tool.

The results of this study do provide evidence that the modified version of the spiritual ecogram has potential for use in family therapy with Native American families. With that said, I support the findings of this study however, I believe that exploration of this spiritual assessment has only just begun. Before clinical use, Elders of Native American groups should review this assessment. Furthermore, this tool has been adapted to promote culturally competent therapy, however it has been recognized that a great amount of knowledge of Indigenous culture should be known before its use. Therapists, who utilize this tool, must also be aware that it may not be appropriate for all Indigenous families. One must explore the family dynamic, connection to Indigenous culture and spirituality before administering such a tool. As a therapist in training, I think it is essential to learn about multicultural issues, especially for work with Indigenous clients. Lastly, the results of this study are supportive to the field of Indigenous psychotherapy as it supports the ideology that many psychotherapeutic tools must be revised to meet the specific needs of Indigenous people.

\section{Indications for further research}

This research is a starting point for providing an effective tool for family therapists to increase cultural competence in their work with Native American families. Although it was merely a step, it provided a framework for potential research on this topic. Future research would need to address the issues presented in this study such as the common weaknesses of spiritual ecograms identified by the participants. One large issue in the study was the language used in the question sets. Future research should develop question sets that are client driven, and can be tailored to reflect the specific needs and interests of the Native family and their tribal customs and beliefs, such as adjusting the framework for taboos and sacred symbols. These aspects need to be incorporated into the use of spiritual ecograms so that the family themselves can be valued as the expert of their own family and spirituality.

The utilization of spiritual ecograms in therapy with Native American families can further be explored by conducting research that examines how effective this tool actually is in therapy with families. The study informed us that spiritual ecograms are considered to be culturally consistent with Native American culture; however, it has not yet been studied if spiritual ecograms statistically show an improvement in therapy when used with Native American families, and how this approach differs when compared to a non-spiritual based approach. This is a potential area of exploration for future research, although careful consideration will have to be taken in response to various ethical concerns related to cross-cultural healing and definitions of healing and wellness and associated measurement tools.

\section{Evaluation of potential contribution to the field of Couples and}




\section{Can spiritual ecograms be utilized in mental health services ...}

\section{Family Psychotherapy}

The results illustrated that spiritual ecograms were moderately consistent with Native American culture and, if used properly, they can help family therapists develop culturally appropriate interventions with Native American families.

Within the core competency domains of marital and family therapy, spirituality is acknowledged as one of the areas that the therapist can recognize the background and the systematic dynamics of the family (Stone Carlson, McGeorge \& Anderson, 2011; Hodge, 2000). However, the domain of spirituality is not often utilized within treatment. This study provides valid information that illustrates the effectiveness of incorporating spirituality into family therapy, especially with Native American family systems, since spirituality is such a foundational role that has an impact on all areas of life for Indigenous peoples.

This research is unique to the field of couples and family psychotherapy because it combines core elements from both genograms and ecomaps to develop a tool that can allow the client to see the big picture of how outside factors can affect relationships within the family system. In the case of the Indigenous population it is important to be able to look at the types of relationships that each family member has with spiritual factors such as the creator, ceremonies, community, and spiritual beings, and how these relationships work with one another (Sutton \& Broken Nose, 1996; Tafoya, 1989).

Another contribution that this research offers to the field of family therapy, is that it recognizes the need to develop an assessment instrument that therapists can use with Indigenous families that has been adapted to incorporate their belief systems and cultural needs. Although the efficacy on utilizing the spiritual ecogram in active therapy with Native American families has not yet been studied, it is crucial (Hodge, 2005b) to understand the elements that will make it most effective as an assessment tool itself before testing its use with a family. This is important given the sensitive nature of many Indigenous ceremonies and beliefs, and the historical trauma that many Indigenous people have endured from colonization and Eurocentric psychotherapeutic practices that are inconsistent with the Indigenous worldview. If questions are not phrased appropriately, considerable harm can occur (Duran, 2006).

This study helps family therapists to incorporate spirituality into their assessment and intervention plans and provides an excellent guide for the appropriate dialogue that can be used when doing so such as, "How would you describe the spiritual journey of your family", and "how was your family's spiritual legacy affected over the generations? Are you aware of the historical events that may have impacted your cultural and spiritual beliefs? (Limb \& Hodge, 2011)," to illustrate a few examples. This research also brings light to certain factors that need to be carefully considered when implementing therapy to a Native American family such as sacred customs and symbols that may not be shared with the therapist, and the importance of understanding and respecting the culture prior to therapy. Furthermore, in order for spiritual assessment tools such as the spiritual ecogram to be used effectively and appropriately, therapists must have the knowledge and competence of Indigenous history and ethics prior to their use.

Finally, this study is important to the contribution on family therapy research because it advances the knowledge in a therapeutic setting by examining the cultural consistency, strengths and limitations of using spiritual ecograms to conduct spiritual assessment with Native American families. The results of this study concluded that the concepts of spiritual ecograms and the question sets involved are moderately consistent with Native American culture. The feedback 


\section{First Peoples Child \& Family Review, Volume 7, Number 1, 2012}

given, as a component of this study, can provide valuable information for the improvement of an ecogram assessment tool.

Overall, the grand themes discussed and the ideas presented within this study were shown to be very useful for developing culturally appropriate techniques that can be used in therapy with Indigenous families. As mentioned earlier, cultural competence is viewed as a process beginning with sensitivity, awareness, and knowledge and then acquiring the appropriate skills necessary for adapting to cross-cultural issues and including them into therapy. Accordingly, if therapists are properly trained in Indigenous culture, and are aware and sensitive to their unique needs, than the spiritual ecogram can be utilized as an effective tool for practicing culturally appropriate couples and family therapy.

\section{References}

Brucker, P.S., \& Perry, B.J. (1998). American Indians: Presenting concerns and considerations for family therapists. American Journal of Family Therapy, 26, 307-319.

Cross, T. (2002). Spirituality and mental health: A Native American perspective. Focal Point, 16(1), 22-24.

DiLorenzo, P., Johnson, R., \& Bussey, M. (2001). The role of spirituality in the recovery process. Child Welfare, 80(2), 257-273.

Duran, E. (2006). Healing the soul wound: Counseling with American Indians and other Native peoples. New York, NY: Teachers College Press.

Frame, M.W.(2000). The spiritual genogram in family therapy. Journal of Marital and Family Therapy, 26, 211-216.

Glasser, B., \& Strauss, A. (1967). The discovery of grounded theory. Chicago, IL: Adeline

Grams, W.A., Carlson, T.S., \& McGeorge, C.R. (2007). Integrating Spirituality into family therapy training: An exploration of faculty member beliefs. Contemporary family therapy, 29(3), 147-161.

Green, B.L. (2010). Culture is treatment: Considering pedagogy in the care of Aboriginal people. Journal of Psychosocial nursing and Mental Health Services, 48 (7), 27-34.

Hardy, K.V., \& Laszoloffy, T.A. (1995). The cultural genogram: Key to training culturally competent family therapists. Journal of Marital and Family Therapy, 21, 227-237.

Hodge, D.R. (2000). Spiritual ecomaps: A new diagrammatic tool for assessing marital and family spirituality. Journal of Marital and Family Therapy, 26(2), 217-228.

Hodge, D.R. (2001). Spiritual genograms: A generational approach to assessing spirituality. Families in Society, 82, 35-48.

Hodge, D.R. (2005a). Spiritual life maps: A client-centered pictorial instrument for spiritual assessment, planning and intervention. Social Work, 50, 77-87.

Hodge, D.R. (2005b). Spiritual ecograms: A new assessment instrument for identifying clients' spiritual strengths in space across time. Families in Society, 86, 287-296.

Hodge, D.R. \& Limb, G.E. (2010). A Native American perspective on spiritual assessment: The strengths and limitations of a complementary set of assessment tools. Health and Social Work, 35(2), 121-131.

Hodge, D.R. \& Williams, T.R. (2002). Assessing African American spirituality with spiritual eco-maps. Families in society, 83, 585-595.

Limb, G. \& Hodge, D.R. (2011). Utilizing spiritual ecograms with Native American families and children to promote cultural competence in family therapy. Journal of Marital and Family Therapy, 37 (1), 81-94.

(c) Nicole Elliott 


\section{Can spiritual ecograms be utilized in mental health services ...}

Paniagua, F.A. (2005). Guidelines for the assessment and treatment of American Indian clients. In F.A. Paniagua (Eds.), Assessing and treating culturally diverse clients (3rd ed., pp. 93-113). Thousand Oaks, CA: Sage.

Siegal, S. (1957). Nonparametric statistics. The American Statistician, 11(3), 13-19.

Stone Carlson, T., McGeorge, C.R., \& Anderson, A. (2011). The importance of spirituality in couple and family therapy: A comparative study of therapists' and educators' beliefs. Contemporary family therapy, 33, 3-16.

Sutton, C., \& Broken Nose, M.A. (1996). American Indian families: An overview. In M. McGoldrick, J. Giordano, J.K. Pearce (Eds.), Ethnicity and family therapy (2nd ed.). New York, NY: Guildford Press.

Tafoya, T. (1989). Circles and Cedar: Native Americans and family therapy. In G.W. Saba, B.M. Karrer, K.V. Hardy (Eds.), Minorities and family therapy. Binghamton, NY: Haworth Press.

Teddlie, C., \& Yu, F. (2007). Mixed methods sampling: A typology with examples. Journal of Mixed Methods Research, $1(1), 72-100$.

Thorne, S. (2000). Data analysis in qualitative research. Evidence-based Nursing, 3(3), 68-70.

Trujillo, A. (2000). Psychotherapy with Native Americans: A view into the role of religion and spirituality. In P.S. Richards \& A.E. Berin (Eds.), Handbook of psychotherapy and religious diversity (pp. 445-466). Washington, DC: American Psychological Association.

Wendt, D.C. \& Gone, J.P. (2011). Rethinking cultural competence: Insights from Indigenous community treatment settings. Transcultural Psychiatry, 49 (2), 206-222. 